\title{
PENGEMBANGAN KARIER TENAGA KEPENDIDIKAN DI BIRO AKADEMIK DAN KEMAHASISWAAN UNIVERSITAS JAMBI
}

\author{
Krisnaini $^{1}$, Suryadi ${ }^{2}$, Siswidiyanto ${ }^{3}$ \\ Program Magister Manajemen Pendidikan Tinggi \\ Fakultas Ilmu Administrasi, Universitas Brawijaya \\ Email:1krisnaini.nai@gmail.com, suryadi_fia@ub.ac.id, siswidiyanto@ub.ac.id
}

\begin{abstract}
The pvrpose of this stody was to determine career development and identify inhibiting factors in the career development of education personnel at the Jambi University Academic and Student Affairs Bureau. This type of research is descriptive qualitative. With the focus of research as follows the career development of education personnel at the Jambi University Academic and Student Affairs Bureau viewed from aspects of work performance assessment, as well as employee education and training. The inhibiting factor in the career development of education personnel at the Jambi University Academic and Student Affairs Bureau is that the Assessment Center has not been implemented to assess and evaluate the competencies of employees, so that feelings of displeasure and getting unfair treatment can be minimized.
\end{abstract}

Keywords: Career development

\begin{abstract}
ABSTRAK
Penelitian ini bertojuan untuk mengetahui pengembangan karier dan mengidentifikasi faktor penghambat dalam pengembangan karier tenaga kependidikan di Biro Akademik dan Kemahasiswaan Universitas Jambi. Jenis penelitian ini adalah kualítatif deskríptif. Dengan fokus penelitian sebagai berikut pengembangan karier tenaga kependidikan di Biro Akademik dan Kemahasiswaan Universitas Jambi dilihat dari aspek penilaian prestasí kerja, serta pendidíkan dan pelatíhan pegawai. Adapun faktor penghambat dalam pengembangan karier tenaga kependidikan di Biro Akademik dan Kemahasiswaan Universitas Jambi yaitu belum terdapat Assẹssment Centẹr untuk menílai dan mengevaluasi kompetensí yang dimiliki pegawai, sehingga perasaan tidak senang dan mendapatkan perlakuan yang tidak adil dapat diminimalkan.
\end{abstract}

\section{Kata kunci: Pengembangan Karier}




\section{A. PENDAHULUAN}

Reformasi Birokrasi yang dilakukan Pemerintah sejak tahun 2010 bertujuan untuk mengurangi dan menghilangkan estimasi publik mengenai birokrasi di Indonesia yang terkesan lambat, bertele-tele dan sering terjadi korupsi. Berdasarkan Peraturan Presiden Nomor 81 tahun 2010 mengamanatkan seluruh kementerian atau lembaga diwajibkan untuk melaksanakan reformasi birokrasi sesuai dengan karakteristik masing-masing institusi. Demikian pula Kemẹnterian Riset, Teknologi dan Pendidíkan Tinggi telah dan sedang melaksanakan Reformasi Birokrasi, termasuk Universitas Jambi (UNJA). Reformasi Birokrasi di Universitas Jambi terdiri dari 8 area perubahan, dimana penguatan sistem manajemen SDM aparatur menjadi salah satu area perubahan yang akan dilakukan. Tujuan area ini untuk memperoleh sistem manajemen administrasi yang mampu menghasilkan pegawai yang professional. Selain itu Universitas Jambi juga akan berstatus sebagai Badan Layanan Umom (BLU) sehingga diperlukan Sumber Daya Manusia yang handal dan profesional.

Pegawai Negeri Sipil diatur sebagai sumber daya aparatur melalui manajemen PNS yang merupakan bagian dari Manajemen ASN. Berdasarkan Undang-Undang Nomor 5 tahun 2014 pasal 1 ayat 5 yaitu Manajemen ASN adalah pengelolaan ASN untuk menghasilkan pegawai ASN yang profesíonal, memiliki nilai dasar, etika profesí, bebas dari intervensi polítik, bersih dari praktik koropsi, kolusi dan nepotisme. Manajemen ASN juga menerapkan sistem merit yang berdasarkan pada kualitas, kompetensi dan peningkatan kinerja. Manajemen PNS merupakan fungsi dalam organisasi yang dirancang untuk memaksimalkan kinerja organisasi.

Berdasarkan 1atar be lakang tersebut, peneliti merumuskan beberapa permasalahan sebagai berikut : 1 ). Bagaimana pengembangan karíer tenaga kependidíkan di Biro Akademik dan Kemahasiswaan Universitas Jambi? 2) Faktor apa saja yang menjadi penghambat pengembangan karíer tenaga kependídikan di Biro Akademik dan Kemahasiswaan Universitas Jambi ?

\section{B. KAJIAN PUSTAKA}

Dalam Manajemen Somber Daya Manusía (MSDM) pengakuan terhadap pentíngnya manusia sebagai sumber daya yang potensíal dan dominan dalam organisasí. Sebagaimana yang dikemukakan oleh Umar (2008:20), dimana MSDM merupakan suatu proses perẹncanaan, pengorganísasian, penggerakan dan pengawasan atas pengadaan, pengembangan, kompensasí, pengintegrasian, pemeliharaan, dan pemutusan hubungan kerja dengan maksud untuk pencapaian tujuan organisasi perusahaan secara terpadu. Dari definisi tersebut, tugas MSDM terdiri dari 3 fungsi yaitu pertama fungsi manajeríal yaitu perencanaan, pengorganísasian, penggerakan dan pengorganisasían; kedua fungsi operasíonal yaitu pengadaan, pengembangan, kompensasí, pengintegrasían, pemeliharaan, dan pemotusan hubungan kerja, dan ketiga fungsi kedudokan MSDM dalam pencapaian tujuan organisasi perusahaan terpado.

Seseorang pegawai bekerja, dengan tujuan awal karena alasan untuk memperoleh penghasilan atau pendapatan dan tidak menganggur. Tetapi lama kelamaan tujuan tersebut berubah dengan adanya keinginan bekerja dengan sunguh-sungguh karena merasa tempat kerja yang dipilih sesuai dengan harapan. Dengan demikian pegawai tersebut merencanakan peningkatan karier ke depan yang lebih baik untuk meningkatkan penghasilan dan kesejahteraannya.

Karier adalah seloruh pekerjaan (jabatan) yang ditangani atau dipegang se 1ama kehidupan kerja seseorang (Handoko, 2014:123). Sedangkan menurut Kasmir (2016:151), karier adalah jabatan dan kepangkatan yang diperoleh seseorang se1ama karyawan bekerja.

Sebagai konsep dasar perencanaan karíer menurut Umar (2008: 30) yaitu :

a. Karier merupakan suatu urutan promosí atau transfer ke jabatan-jabatan yang lebih besar tanggungjawabnya atau ke 1okasilokasi yang lebih baik selama kehidupan kerja seseorang.

b. Karier merupakan petunjuk pekerjaan yang membentuk suatu po1a kemajuan yang sistematik dan jelas (membentuk satu ja1ur karier).

c. Karier merupakan sejarah pekerjaan seseorang atau serangkaían posisi yang dipegang selama kehidupan kerja.

$$
\text { Menurut Handoko (2014:123), }
$$

pengembangan karier adalah peningkatanpeningkatan pribadí yang dilakukan seseorang untuk mencapai suatu rencana karier. Dalam praktíknya beberapa faktor 
yang mempengaruhi karier, baik secara langsung maupun tidak 1angsung menurut Kasmir (2016:157-159) yaitu :

1. Kínerja merupakan hasil kerja atau perilaku kerja seseorang dalam suatu periode.

2. Motívasi kerja merupakan dorongan atau rangsangan kepada seseorang untuk melakukan suatu kegíatan.

3. Komítmen merupakan kepatohan seseorang terhadap ucapan, tindakan, peraturan atau kebijakan perusahaan.

4. Kepvasan kerja adalah tingkat perasaan seseorang atas sesuatu yang telah dilakukannya.

5. Kedisíplinan merupakan tindakan seseorang untuk mengikuti seluruh peratoran yang dikeluarkan oleh pẹrusahaan.

6. Kompensasí merupakan ba1as jasa yang diberikan perusahaan kepada karyawan, baik yang berbentuk kevangan, maupun non kevangan.

7. Loyalítas adalah kesetíaan seseorang kepada perusahaan, seseorang yang loyal kepada perusahaan.

8. Pendidíkan dan pelatihan merupakan kegiatan seseorang karyawan untuk mengasah dan menambah pengetahoan, kemampuan dan keterampilannya, sehingga mampu melakukan pekerjaannya dengan baik.

9. Kepemímpinan merupakan orang atau atasan yang diberi tugas, wewenang dan tanggungjawab kepada seseorang, termasuk dalam memberikan penilaian.

10. Upaya kerja merupakan usaha seseorang untuk melakukan atau mencapai sesuatu secara songguh-sungguh.

11. Semangat kerja yang tínggi akan dapat mempengaruhi karíer.

\section{METODE PENELITIAN}

Jenis penelitian ini adalah penelitian kualitatíf yaitu penelitian dilakukan untuk mengetahuí atau menggambarkan secara rinci mengenai pengembangan karíer di Biro Akademik dan Kemahasiswaan Universitas Jambi. Pendekatan deskríptif juga dilakukan untuk memberikan gambaran yang menyeluruh dan jelas terhadap sítuasi sosíal yang diteliti, komparatíf berbagai peristiwa dari situasi sosial satu dengan sitvasi sosial yang lain atau dari waktu yang laín; atau dapat menemokan pola-pola hubungan antara aspek tertento dengan aspek yang lain (Sugiyono, 2016:227).

Adapun fokvs penelitian sebagai berikut : 1 . Pengembangan karíer tenaga kependídikan di Biro Akademik dan Kemahasiswaan Universitas Jambi dilihat melalui aspek penílaian prestasí kerja dan pendidíkan dan pelatíhan. 2) Faktor penghambat pengembangan karier tenaga kependídikan di Biro Akademik dan Kemahasiswaan Universitas Jambi.

\section{HASIL DAN PEMBAHASAN}

Analisis pengembangan karier tenaga kependidikan di Biro Akademik dan Kemahasiswaan Universitas Jambi dalam penelitian ini, difokuskan pada aspek penilaian prestasi kerja dan pendidikan dan pelatihan. Deskripsi pengembangan karier tenaga kependidikan di Biro Akademik dan Kemahasiswaan Universitas Jambi sebagai berikut :

\section{Penílaian prestasí kerja}

Penilaían prestasí kerja PNS terdiri dari unsur SKP dan perilaku kerja. Sasaran Kerja Pegawai (SKP) merupakan rẹncana kerja dan target yang akan dicapai oleh seorang PNS. Penilaian Prestasí Kerja PNS merupakan suatu proses penilaian secara sistematís yang dilakukan oleh pejabat penilai terhadap sasaran kerja pegawai dan perilako PNS. Hal ini sesuai dengan pernyataan Kepala Biro Akademik dan Kemahasiswaan Universitas Jambi sebagai berikut :

" Ketika melihat SKP pegawai tinggi yang perlu diperhatikan tidak hanya sasaran kerja dan perilaku kerja pegawai tersebut, tetapi ada faktor pendukung lain yang diperhatikan. Faktor pendukung lain yaitu adanya penilaian dari pimpinan tentang tanggung jawab menyelesaikan suatu pekerjaan, berdedikasi dan memiliki loyalitas yang tinggi. Disiplin pegawai pun akan menjadi penilaian. Penilaian disiplin tidak hanya dilihat dari presensi pegawai datang dan pulang tepat waktu tetapi kehadiran dan menyelesaikan tugas dan bertanggung jawab serta dapat menyelesaikan tugas tersebut tepat waktu ". (wawancara dilakukan pada tanggal 16 April 2019)

Hal yang sama juga dijelaskan oleh Kepala Bagian Akademik dan Kerjasama yang menyatakan bahwa : 
" Prestasi kerja pegawai merupakan kinerja yang dihasilkan oleh seorang pegawai sesuai dengan yang diinginkan oleh pimpinan atas suatu pekerjaan dan pekerjaan tersebut dapat selesaikan sesuai dengan waktu yang ditentukan. Selain itu, disiplin pegawai juga dapat dijadikan penilaian prestasi kerja. Apakah pegawai tersebut datang dan pulang tepat waktu serta memperhatikan tugas dan tanggungjawab pekerjaan yang diberikan dapat diselesaikan tepat waktu. Dalam arti kata pegawai tersebut disiplin dalam melaksanakan tugas dan tanggungjawab yang diberikan ". (wawancara dilakukan pada tanggal 18 April 2019)

Begitu juga dengan apa yang disampaíkan oleh Kepala Bagian Pengembangan Mahasiswa dan Alumni yang menyatakan bahwa :

" Penilaian prestasi kerja pegawai dapat dilihat dari catatan harian dari pimpinan, Sasaran Kerja Pegawai (SKP) berupa capaian kerja yang dihasilkan dan perilaku kerjanya berupa orientasi pelayanan, integritas, komitmen, disiplin, kerja sama dan kepemimpinan menjadi bahan pertimbangan bagi pimpinan. Yang lebih utama adalah dapat bekerja sama sebagai sebuah tim yang solid untuk dapat menyelesaikan pekerjaan dengan baik. Kebijakan pimpinan pun tidak terlepas untuk memberikan penilaian prestasi kerja bawahannya ". (wawancara dilakukan pada tanggal 18 April 2019)

Pendapat ínforman sesuai dengan pendapat ahlí, Dale Yoder dalam Hasíbuan (2016:88-89), yang mengatakan bahwa ruang lingkup penilaian prestasi mencakup apa yang dinílai, kenapa dinilaí, dimana penilaian dilakukan, kapan penilaían dilakukan, síapa yang akan dinílai dan bagaimana menilaínya. Dengan kata lain, penílaian prestasí kerja pegawai dapat dilihat ruang lingkupnya melalui SKP pegawaí masíng-masing.

\section{Pendidikan dan pelatihan}

Pendidikan dan Pelatihan bagi SDM aparatur pelayanan publik memberikan kontribusi yang dominan terhadap peningkatan kualitas pelayanan yang prima dan berkualitas. Pendidikan dan Pelatihan memiliki dampak positif berdasarkan pencapaian pengetahuan dan keterampilan yang dimiliki oleh pegawai. Hal yang sama juga dijelaskan oleh Kepala Bagian Akademik dan Kerjasama yang menyatakan bahwa :

"Pendidikan dan pelatihan PNS dimulai dari Diklat Prajabatan, kemudian ada Diklat Teknis seperti diklat bendahara pengeluaran, diklat analisis jabatan, diklat protokolan dan lain-lain, serta Diklat kepemimpinan. Selama mengikuti berbagai macam diklat pegawai akan memperoleh pengetahuan dan keterampilan serta dapat sharing atau berbagi pengalaman kepada teman-teman maupun widyaiswara sehingga dijadikan masukan bagi yang lain. Kemenristekdikti sebagai penyelenggara diklat akan meminta daftar usulan peserta yang akan mengikuti diklat prajabatan dan diklat kepemimimpinan serta menawarkan berbagai macam diklat teknis yang dapat diikuti pegawai ". (wawancara dilakukan pada tanggal 18 April 2019)

Pendapat lain juga dikemukakan oleh Kepala Bagian Pengembangan Mahasiswa dan Alumni yang menyatakan bahwa :

" Diklat Prajabatan, Diklat Teknis, Diklat Kepemimpinan serta Bimtek yang diselenggarakan oleh Kemenristekdikti diperuntukkan bagi PNS di Universitas untuk dapat meningkatkan pengetahuan dan keterampilannya. Seperti untuk pejabat struktural ada penjenjangan diklat jabatan yaitu diklatpim IV, diklatpim III maupun diklatpim II. Dengan telah mengikuti diklat maka kemampuan konseptual, kemampuan manajerial dan kemampuan teknis akan meningkat ". (wawancara dilakukan pada tanggal 18 April 2019)

Pendapat ínforman sesuai dengan pendapat ahli, Hasíbuan (2016:69) pengembangan adalah suatu vsaha untuk meningkatkan kemampuan teknís, teorítis, konseptval dan moral karyawan sesuai dengan kebotuhan pekerjaan/jabatan melalui pendídikan dan pelatihan.

\section{Faktor penghambat}

Faktor penghambat dalam pengembangan karier tenaga kependidikan di Biro Akademik dan Kemahasiswaan Univeritas Jambi yaitu belum ada Assessment Center untuk untuk menilai dan mengevaluasi kompetensi yang dimiliki oleh seorang pegawai. Saat ini Universitas Jambi baru 
menggunakan assessment untuk eselon II, sedangkan eselon III dan eselon IV masih belum diterapkan proses assessment. Sebagaimana yang dikemukakan oleh Kepala Biro Akademik dan Kemahasswaan yang menyatakan bahwa :

"Saat ini assessment baru dilakukan untuk jabatan pimpinan tinggi pratama sedangkan untuk jabatan administrator belum dilakukan. Untuk masa depan, hal ini dapat dilakukan agar diperoleh pejabat struktural yang sesuai dengan kompetensinya dan secara adil setiap pegawai memiliki kesamaan untuk duduk dalam suatu jabatan ". (wawancara dilakukan pada tanggal 16 April 2019)

\section{E. KESIMPULAN DAN SARAN}

\section{Kesimpulan}

Berdasarkan hasíl yang ditemokan bahwa pengembangan karíer tenaga kependidikan di Biro Akademik dan Kemahasiswaan Universitas Jambi dapat disimpolkan belum maksimal dengan rincian sebagai berikut :

a. Pengembangan karíer tenaga kependidíkan di Biro Akademik dan Kemahasiswaan Universitas Jambi dilihat dari aspek penílaian kerja dari hasíl wawancara dan data SKP yang diperoleh dari informan perlu dilakukan perbaíkan dímasa datang, bukan berdasarkan hallo effect. Sedangkan pengembangan karíer tenaga kependídikan di Biro Akademik dan Kemahasiswaan Universitas Jambi dilihat dari aspek pendídikan dan pelatíhan, khususnya pendídikan dan pelatihan kepemímpinan masih belum terlaksana dengan baik karena masih terdapat pejabat struktoral yang belum mengikuti Diklatpím dan menunggu panggilan untuk menjadi peserta diklatpim dari Kemenristekdíkti.

b. Faktor penghambat pengembangan karíer tenaga kependídikan di Biro Akademik dan Kemahasiswaan Universitas Jambi yaitu belum ada Assessment Center untuk untuk menílai dan mengevalvasi kompetensí yang dimilíki oleh seorang pegawaí.
Hal yang sama juga dijelaskan oleh Kepala Bagian Hukum dan Kepegawaian yang menyatakan bahwa :

" Agar pelaksanaan dalam pemilihan jabatan struktural dapat berjalan dengan baik dan berlaku adil bagi setiap pegawai ke depan direncanakan proses assessment. Jadi pegawai yang telah memiliki pendidikan, pangkat/golongan ruangan, masa kerja dan pengalaman kerja secara terbuka dapat mengikuti tes. Dari assessment akan diperoleh pegawai yang memang berkompeten ". (wawancara dilakukan pada tanggal 11 April 2019).

\section{Saran}

Saran yang diberíkan oleh penelíti yaitu Universitas Jambi hendaknya mulai menyíapkan Assessment Cẹnter untuk dapat menyeleksí dan memilíh pegawai yang berkompẹten untuk duduk dalam jabatan struktoral. Jabatan struktoral tersebut merupakan jenjang karíer yang diharapkan oleh setíap pegawai. Karena itu pengembangan karíer pegawai harus disíapkan sedíni mungkín. Dalam penelitain ini penelíti hanya menggunakan dua aspek penílaian untuk pengẹmbangan karíer tenaga kependídikan, untuk penelíti selanjutnya dapat menggunakan banyak aspek agar dapat diketahuí bagaímana pengembangan karíer dengan aspek laínnya.

\section{DAFTAR PUSTAKA}

Handoko, T. Hani. 2014. Manajemen Personalia dan Sumberdaya Manusia. BPFE. Yogyakarta.

Hasibuan, Malayu. 2016. Manajemen Sumber Daya Manusia Edisi Revisi. Penerbit Bumi Aksara. Jakarta.

Kasmir. 2016. Manajemen Sumber Daya Manusia (Teori dan Praktik). Rajawali Pers. PT. RajaGrafindo Persada. Depok.

Umar, Husien. 2008. Desain Penelitain MSDM dan Perilaku Karyawan Paradigma Positivistik dan Berbasis Pemecahan Masalah. Rajawali Pers PT RajaGrafindo Persada. Jakarta. 
Sugiyono. 2016. Memahami Penelitian Kualitatif. Penerbit Alfabeta.

Bandung.

Peraturan Pemerintah Nomor 101 tahun 2000 tentang Pendidikan dan Pelatihan Jabatan Pegawai Negeri Sipil.

Peraturan Pemerintah Nomor 13 tahun 2002 tentang perubahan atas Peraturan Pemerintah Nomor 100 tahun 2000 tentang Pengangkatan Pegawai Negeri Sipil dalam Jabatan Struktural.

Peraturan Pemerintah Nomor 46 tahun 2011 tentang Penilaian Prestasi Kerja Pegawai Negeri Sipil.

Peraturan Pemerintah Nomor 11 tahun 2017 tentang Manajemen Pegawai Negeri Sipil.

Peraturan Menteri Pendidikan dan Kebudayaan Nomor 19 tahun 2014 tentang Organisasi dan Tata Kerja Universitas Jambi. 